\title{
Erratum to: Loss modeling using Burr mixtures
}

\author{
S. A. Abu Bakar ${ }^{1}$ - Saralees Nadarajah ${ }^{2}$. \\ Z. A. Absl Kamarul Adzhar ${ }^{1}$
}

Published online: 9 August 2017

C) Springer-Verlag GmbH Germany 2017

\section{Erratum to: Empir Econ DOI 10.1007/s00181-017-1269-7}

In the original publication of the article, the funding note is inadvertently missed in acknowledgement section. The correct acknowledgement is given below.

Acknowledgements The authors would like to thank the Editor and the referee for careful reading and comments which greatly improved the paper. This research was supported by Fundamental Research Grant Scheme (FRGS FP050-2014A), Ministry of Higher Education Malaysia.

The online version of the original article can be found under doi:10.1007/s00181-017-1269-7.

Saralees Nadarajah

saralees.nadarajah@manchester.ac.uk

1 Institute of Mathematical Sciences, University of Malaya, 50603 Kuala Lumpur, Malaysia

2 School of Mathematics, University of Manchester, Manchester M13 9PL, UK 